\title{
El Patrimonio Cultural Inmaterial Para Generar Un Espacio De Reflexión Social. Estudio De Caso: Comunidad De Nizag, Provincia De Chimborazo, Ecuador
}

\author{
Daniela Paulina Castillo Ortíz \\ Sandra Patricia Miranda Salazar \\ Christiam Paúl Aguirre Merino \\ Libeth Lucía Urgiléz Pinos
}

Escuela Superior Politécnica del Chimborazo

Facultad de Recursos Naturales

doi: 10.19044/esj.2016.v12n23p184 URL:http://dx.doi.org/10.19044/esj.2016.v12n23p184

\begin{abstract}
This case study describes non-tangible elements of the cultural heritage of the community of Nizag, Ecuador. We found a social dynamic built on regional cultural events, including oral traditions and expressions, performing arts, social practices, rituals and festivals, ancestral knowledge of nature and the universe, and traditional artisanship. Linking these categories permitted us to understand intergenerational transmission of heritage and related cultural integrity in this indigenous community. The written record of the living memory of its inhabitants, a heritage registry, allowed the creation of spaces for reflection and self-awareness, reflecting the need to reaffirm the culture and its value for traditional knowledge holders and for new generations, in order to guarantee its reproduction and use for sustainable community tourism. The representativeness of this heritage registry created during community workshops, in part through affirmation of its elements by community members, regained a necessary condition of respect for human rights and diversity among them. Furthermore, the sustainability of tourism involving non-tangible cultural heritage requires putting in place values of equity and solidarity. Making memories more significant, while ensuring their accurate reproduction and enhancing their symbolic value to tourists who visit, not only enriches the experiences of what they share, but also recovers the social and cultural significance of heritage itself.
\end{abstract}

Keywords: Non-tangible cultural heritage, social reflection, living memory, community of Nizag, sustainable tourism 


\section{Resumen}

El patrimonio cultural inmaterial de la comunidad de Nizag, Ecuador, en donde se realizó el estudio de caso evidencia una dinámica social que se alimenta de manifestaciones culturales pertenecientes a los ámbitos de: tradiciones y expresiones orales; artes del espectáculo; usos sociales, rituales y actos festivos; conocimientos y saberes ancestrales de la naturaleza y el universo; y técnicas artesanales tradicionales. La vinculación de estos ámbitos permitió conocer la situación de transmisión intergeneracional del patrimonio, así como su vigencia cultural en esta comunidad indígena. El registro de la memoria viva de sus habitantes ha permitido la creación de espacios de reflexión, de concientización de aquello que es propio, así como la necesidad de reafirmar la cultura y valorar a los poseedores de la memoria para que las nuevas generaciones garanticen su reproducción y el aprovechamiento para la sostenibilidad del turismo comunitario que realizan. La representatividad que nace a través del reconocimiento comunitario de los elementos del registro patrimonial en los talleres comunitarios, recuperó el estado de respeto a los derechos y a la diversidad del que son sujetos. Además, reflexionar sobre la sostenibilidad del turismo desde el patrimonio cultural inmaterial implica practicar valores de equidad, solidaridad; para que al profundizar en la memoria y en su recreación exacta, el dotar de un valor simbólico a las visitas de los turistas, no sólo enriquezcan las vivencias y aquello que se comparte, sino que se recupera el sentido social y cultural del patrimonio.

Palabras claves: Patrimonio cultural inmaterial, reflexión social, memoria viva, comunidad de Nizag, turismo sostenible.

\section{Introducción}

El Ecuador es parte del Convenio de la Diversidad Biológica y forma parte de los países megadiversos del mundo, según la Declaración de Cancún 2002 (Programa de las Naciones Unidas para el Medio Ambiente, 2002, pág. 1). En su territorio conviven 14 nacionalidades y 18 pueblos reconocidos por el Estado, que confirman la identidad plurinacional, pluricultural y multiétnica del país, que lo vuelve único a nivel de América Latina. Estos elementos incentivan la investigación, conservación y puesta en valor del patrimonio natural y cultural de la Nación.

El turismo en la actualidad es una de las actividades que dinamiza la economía mundial, con cifras exponenciales por ingresos de 1.425.000 millones de dólares en el año 2014 por movimientos de turistas internacionales (Organización Mundial del Turismo, 2015, pág. 2). En el Ecuador se registra en el mismo año, ingresos económicos por 1.086,5 
millones de dólares por dicha actividad (Coordinación General de Estadística e Investigación del Ministerio de Turismo del Ecuador, 2015, pág. 7); demostrando que el turismo se ha convertido en un fenómeno social, cultural y económico global (Organización Mundial de Turismo, 2016) y que para el país, significa una contribución al desarrollo nacional, la erradicación de la pobreza y que aporta al Buen Vivir, en donde se incluye la valorización y conservación del patrimonio turístico sustentado en un desarrollo equilibrado del territorio (Ministerio de Turismo del Ecuador, 2007, pág. 19).

En este contexto, se hace necesario reconocer los beneficios que se derivan del turismo sostenible, en especial entre la relación turismo patrimonio, tal como lo es la dinamización económica y el sentido de pertenencia de una población. Por tanto se hace imprescindible fomentar un turismo que respete la autenticidad cultural de las comunidades anfitrionas, la conservación de sus activos naturales, arquitectónicos, valores tradicionales, que contribuyen al entendimiento y a la tolerancia intercultural (Organización Mundial del Turismo, 2016).

La valoración del patrimonio en su ámbito integral (natural y cultural) desde el turismo sostenible, permite que el testimonio de cada persona exprese su capacidad creativa y de identidad, que ayuda además en la diversidad cultural a través de la constante circulación de los elementos simbólicos que representan las memorias colectivas e individuales y el patrimonio cultural material e inmaterial (Secretaría Nacional de Planificación y Desarrollo, 2014, pág. 182).

En este sentido el patrimonio cultural inmaterial comprende expresiones ancestrales vivas transmitidas de generación en generación; que pese a su fragilidad, se convierte en un importante factor del mantenimiento de la diversidad cultural frente a la creciente globalización (Organización de las Naciones Unidas para la Educación, la Ciencia y la Tecnología, 2016). Para muchas poblaciones especialmente para los grupos minoritarios y las poblaciones indígenas, el patrimonio intangible representa la fuente vital de una identidad profundamente arraigada en la historia y constituye los fundamentos de la vida comunitaria. Sin embargo la protección de este patrimonio constantemente amenazado es muy vulnerable debido a su índole efímera. (Centro de Información de las Naciones Unidas, 2002)

En la provincia de Chimborazo existen evidencias arqueológicas de la ruta milenaria Qhapaq Ñan (Camino del Inca o Camino Principal Andino) declarado como Patrimonio Cultural de la Humanidad por el Comité de Patrimonio Mundial de la UNESCO (United Nations Educational, Scientific and Cultural Organization), el 22 de junio del 2014 sección $38^{\circ}$ realizado en Doha - Qatar (Organización de las Naciones Unidas para la Educación, la Ciencia y la Cultura, 2014, pág. 241), que permitieron una apropiación simbólica de las culturas precolombinas por un lado (Narrío, Alausí, Cañari, 
Puruhá), y la apropiación simbólica de las comunidades vivas actuales como Nizag, que aprovecha en el desarrollo del turismo comunitario atractivos como la Nariz del Diablo y el Camino del Inca (Aguirre Merino, 2015, pág. $12)^{14}$.

Nizag es una comunidad indígena de 2.100 habitantes identificada con el Pueblo Puruhá de la Nacionalidad Kichwa, localizada al sur del cantón Alausí, provincia de Chimborazo. Está asentada en las faldas del cerro Cóndor Puñuna a una altitud de 2.525 m.s.n.m., a una latitud de 9753056 y longitud de 7409530 UTM (Goberno Autónomo Descentralizado Cantonal de Alausí, 2014) y está relacionada a un ramal del Qhapaq Ñan.

La visibilización del patrimonio cultural inmaterial para la reflexión social es el punto central de esta investigación, de tal modo que se evidenció los aportes en la salvaguardia cultural, la dinamización económica y en el Buen Vivir (Secretaría Nacional de Planificación y Desarrollo, 2014) de las comunidades.

\section{Método}

La investigación se realizó a través del estudio de caso de la comunidad de Nizag, aplicando los métodos descriptivo y dialéctico. El descriptivo usado en la descripción de las manifestaciones culturales reconocidas por la UNESCO y el dialéctico empleado en la valoración colectiva del patrimonio cultural de la comunidad de Nizag. El enfoque de la investigación fue predominantemente cualitativo.

\section{Técnicas e instrumentos}

Se llevó a cabo usando técnicas de investigación participativa, bibliográfica y de campo.

- Se realizó el levantamiento de la información primaria a través de talleres participativos con el Grupo de Artesanas de Nizag y la Organización de Turismo Comunitario de Nizag (portadores claves del conocimiento ancestral de Nizag respecto a los habitantes más antiguos de la comunidad). Para esto se utilizó la Guía Etnográfica (Guerrero Arias, 2002, págs. 27-65) con su respectivo instrumento de ficha de observación, aplicando la técnica de entrevista con el respectivo instrumento de guía de entrevista.

- Para la identificación y descripción de las manifestaciones culturales de la comunidad de Nizag, la técnica que se usó fue la investigación de campo, respaldada en la metodología del "Instructivo para Fichas de Registro e Inventario del Patrimonio Cultural Inmaterial” del (Instituto

${ }^{14}$ Existen autores como Fresco, Antonio; e Idrovo, Jaime que también realizan estudios referentes al Qhapaq Ñan. 
Nacional de Patrimonio Cultural del Ecuador, 2012, págs. 47-133), con el instrumento de la ficha de registro (ver anexo A). Los ámbitos a investigar aplicando dicha metodología fueron:

- $\quad$ Tradiciones y expresiones orales.

- $\quad$ Artes del espectáculo.

- $\quad$ Usos sociales, rituales y actos festivos.

- $\quad$ Conocimientos y usos relacionados con la naturaleza y el universo.

- Técnicas artesanales tradicionales.

- $\quad$ Se validó el análisis situacional de las manifestaciones culturales aplicando la técnica de investigación participativa mediante talleres con el Grupo de Artesanas de Nizag, Catequistas de la comunidad y la Organización de Turismo Comunitario de Nizag. Esto mediante la metodología del "Instructivo para Fichas de Registro e Inventario del Patrimonio Cultural Inmaterial" del (Instituto Nacional de Patrimonio Cultural del Ecuador, 2012, págs. 47-133), para calificar los criterios de cada recurso cultural con la ficha técnica de validación. Se evaluaron los siguientes parámetros:

- Vinculación a los ámbitos del patrimonio inmaterial.

- $\quad$ Transmisión intergeneracional y vigencia.

- $\quad$ Representatividad y reconocimiento comunitario y/o colectivo.

- $\quad$ Respeto a los derechos.

- $\quad$ Equidad.

- $\quad$ Respeto a la diversidad.

- $\quad$ Sentido social y cultural.

\section{Resultados}

\section{Inventario del Patrimonio Cultural Inmaterial}

Cuadro 1: Registro del patrimonio cultural inmaterial (PCI) y de la memoria viva

\begin{tabular}{|c|c|c|c|c|}
\hline Código & $\begin{array}{c}\text { Denominación del } \\
\text { PCI y memoria viva }\end{array}$ & Ámbito & Subámbito & Detalle del Subámbito \\
\hline $\begin{array}{c}\text { Im-06-02-50- } \\
001-15- \\
000001\end{array}$ & $\begin{array}{l}\text { Montaña Cóndor } \\
\text { Puñuna }\end{array}$ & $\begin{array}{l}\text { Tradiciones y } \\
\text { Expresiones } \\
\text { Orales }\end{array}$ & Leyendas & $\begin{array}{l}\text { Leyendas Asociadas a } \\
\text { Elementos Naturales }\end{array}$ \\
\hline $\begin{array}{c}\text { Im-06-02-50- } \\
\text { 001-15- } \\
000002 \\
\end{array}$ & Leyenda Cruzpamba & $\begin{array}{c}\text { Tradiciones y } \\
\text { Expresiones } \\
\text { Orales } \\
\end{array}$ & Leyendas & $\begin{array}{l}\text { Leyendas Asociadas a } \\
\text { Elementos Naturales }\end{array}$ \\
\hline $\begin{array}{c}\text { Im-06-02-50- } \\
001-15- \\
000003\end{array}$ & $\begin{array}{l}\text { Leyenda Abra La } \\
\text { Puerta Señora }\end{array}$ & $\begin{array}{l}\text { Tradiciones y } \\
\text { Expresiones } \\
\text { Orales }\end{array}$ & Leyendas & $\begin{array}{c}\text { Leyendas Asociadas a } \\
\text { Apariciones de Seres } \\
\text { Sobrenaturales }\end{array}$ \\
\hline $\begin{array}{c}\text { Im-06-02-50- } \\
001-15- \\
000004 \\
\end{array}$ & $\begin{array}{l}\text { Cuento Novio } \\
\text { Cóndor }\end{array}$ & $\begin{array}{l}\text { Tradiciones y } \\
\text { Expresiones } \\
\text { Orales } \\
\end{array}$ & Leyendas & $\begin{array}{l}\text { Leyendas Asociadas a } \\
\text { Elementos Naturales }\end{array}$ \\
\hline $\begin{array}{c}\text { Im-06-02-50- } \\
001-15- \\
000005 \\
\end{array}$ & Cuento Wantugaya & $\begin{array}{l}\text { Tradiciones y } \\
\text { Expresiones } \\
\text { Orales } \\
\end{array}$ & $\begin{array}{l}\text { Expresiones } \\
\text { Orales }\end{array}$ & Cuentos \\
\hline
\end{tabular}




\begin{tabular}{|c|c|c|c|c|}
\hline $\begin{array}{c}\text { Im-06-02-50- } \\
\text { 001-15- } \\
000006 \\
\end{array}$ & Coplas de Carnaval & $\begin{array}{l}\text { Tradiciones y } \\
\text { Expresiones } \\
\text { Orales } \\
\end{array}$ & $\begin{array}{l}\text { Expresiones } \\
\text { Orales }\end{array}$ & Coplas \\
\hline $\begin{array}{c}\text { Im-06-02-50- } \\
001-15- \\
000007\end{array}$ & $\begin{array}{c}\text { Supersticiones, } \\
\text { Dichos y Creencias }\end{array}$ & $\begin{array}{l}\text { Tradiciones y } \\
\text { Expresiones } \\
\text { Orales }\end{array}$ & $\begin{array}{l}\text { Expresiones } \\
\text { Orales }\end{array}$ & $\begin{array}{c}\text { Proverbios, Dichos, } \\
\text { Supersticiones y } \\
\text { Creencias }\end{array}$ \\
\hline $\begin{array}{c}\text { Im-06-02-50- } \\
002-15- \\
000008 \\
\end{array}$ & Danza Los Yumbos & $\begin{array}{c}\text { Artes del } \\
\text { Espectáculo }\end{array}$ & Danza & N/A \\
\hline $\begin{array}{c}\text { Im-06-02-50- } \\
002-15- \\
000009\end{array}$ & Danza El Capitán & $\begin{array}{c}\text { Artes del } \\
\text { Espectáculo }\end{array}$ & Danza & N/A \\
\hline $\begin{array}{c}\text { Im-06-02-50- } \\
\text { 002-15- } \\
000010 \\
\end{array}$ & $\begin{array}{c}\text { Danza El Tejido de } \\
\text { Cintas }\end{array}$ & $\begin{array}{c}\text { Artes del } \\
\text { Espectáculo }\end{array}$ & Danza & N/A \\
\hline $\begin{array}{c}\text { Im-06-02-50- } \\
\text { 002-15- } \\
000011 \\
\end{array}$ & Juegos Tradicionales & $\begin{array}{c}\text { Artes del } \\
\text { Espectáculo }\end{array}$ & $\begin{array}{c}\text { Juegos } \\
\text { Tradicionales }\end{array}$ & $\begin{array}{c}\text { Juegos Rituales o } \\
\text { Festivos }\end{array}$ \\
\hline $\begin{array}{c}\text { Im-06-02-50- } \\
\text { 002-15- } \\
000012 \\
\end{array}$ & Haway & $\begin{array}{c}\text { Artes del } \\
\text { Espectáculo }\end{array}$ & Música & N/A \\
\hline $\begin{array}{c}\text { Im-06-02-50- } \\
003-15- \\
000013\end{array}$ & Fiesta de Hotava & $\begin{array}{l}\text { Usos Sociales y } \\
\text { Actos Festivos }\end{array}$ & Fiestas & $\begin{array}{c}\text { Otras Celebraciones } \\
\text { Festivas }\end{array}$ \\
\hline $\begin{array}{c}\text { Im-06-02-50- } \\
003-15- \\
000014 \\
\end{array}$ & Fiesta de Tres Reyes & $\begin{array}{l}\text { Usos Sociales y } \\
\text { Actos Festivos }\end{array}$ & Fiestas & $\begin{array}{c}\text { Fiestas o } \\
\text { Conmemoraciones } \\
\text { Religiosas } \\
\end{array}$ \\
\hline $\begin{array}{c}\text { Im-06-02-50- } \\
\text { 003-15- } \\
000015 \\
\end{array}$ & $\begin{array}{c}\text { Fiesta de Tayta } \\
\text { Carnaval }\end{array}$ & $\begin{array}{l}\text { Usos Sociales y } \\
\text { Actos Festivos }\end{array}$ & Fiestas & $\begin{array}{c}\text { Fiestas o } \\
\text { Conmemoraciones } \\
\text { Religiosas } \\
\end{array}$ \\
\hline $\begin{array}{c}\text { Im-06-02-50- } \\
\text { 003-15- } \\
000016 \\
\end{array}$ & $\begin{array}{c}\text { Fiesta de Corpus } \\
\text { Christi }\end{array}$ & $\begin{array}{l}\text { Usos Sociales y } \\
\text { Actos Festivos }\end{array}$ & Fiestas & $\begin{array}{c}\text { Fiestas o } \\
\text { Conmemoraciones } \\
\text { Religiosas } \\
\end{array}$ \\
\hline $\begin{array}{c}\text { Im-06-02-50- } \\
003-15- \\
000017 \\
\end{array}$ & Día de Los Difuntos & $\begin{array}{l}\text { Usos Sociales y } \\
\text { Actos Festivos }\end{array}$ & Fiestas & $\begin{array}{c}\text { Fiestas o } \\
\text { Conmemoraciones } \\
\text { Religiosas } \\
\end{array}$ \\
\hline $\begin{array}{c}\text { Im-06-02-50- } \\
003-15- \\
000018\end{array}$ & $\begin{array}{c}\text { Concurso de Años } \\
\text { Viejos }\end{array}$ & $\begin{array}{l}\text { Usos Sociales y } \\
\text { Actos Festivos }\end{array}$ & Fiestas & $\begin{array}{c}\text { Otras Celebraciones } \\
\text { Festivas }\end{array}$ \\
\hline $\begin{array}{c}\text { Im-06-02-50- } \\
\text { 003-15- } \\
000019 \\
\end{array}$ & $\begin{array}{c}\text { La Minga y Presta } \\
\text { Mano }\end{array}$ & $\begin{array}{l}\text { Usos Sociales y } \\
\text { Actos Festivos }\end{array}$ & $\begin{array}{c}\text { Prácticas } \\
\text { Comunitarias } \\
\text { Tradicionales } \\
\end{array}$ & N/A \\
\hline $\begin{array}{c}\text { Im-06-02-50- } \\
003-15- \\
000020 \\
\end{array}$ & Pampamesa & $\begin{array}{l}\text { Usos Sociales y } \\
\text { Actos Festivos }\end{array}$ & $\begin{array}{c}\text { Prácticas } \\
\text { Comunitarias } \\
\text { Tradicionales } \\
\end{array}$ & N/A \\
\hline $\begin{array}{c}\text { Im-06-02-50- } \\
\text { 003-15- } \\
000021 \\
\end{array}$ & Fiesta de La Cosecha & $\begin{array}{l}\text { Usos Sociales y } \\
\text { Actos Festivos }\end{array}$ & Ritos & Ritos Propiciatorios \\
\hline $\begin{array}{c}\text { Im-06-02-50- } \\
\text { 003-15- } \\
000022 \\
\end{array}$ & $\begin{array}{c}\text { Ritos Asociados al } \\
\text { Nacimiento de un } \\
\text { Niño } \\
\end{array}$ & $\begin{array}{l}\text { Usos Sociales y } \\
\text { Actos Festivos }\end{array}$ & Ritos & Ritos de Paso \\
\hline $\begin{array}{c}\text { Im-06-02-50- } \\
003-15- \\
000023 \\
\end{array}$ & $\begin{array}{l}\text { Enamoramiento y } \\
\text { Matrimonio }\end{array}$ & $\begin{array}{l}\text { Usos Sociales y } \\
\text { Actos Festivos }\end{array}$ & Ritos & Ritos de Paso \\
\hline Im-06-02-50- & El Funeral & Usos Sociales y & Ritos & Ritos de Paso \\
\hline
\end{tabular}




\begin{tabular}{|c|c|c|c|c|}
\hline $\begin{array}{l}003-15- \\
000024\end{array}$ & & Actos Festivos & & \\
\hline $\begin{array}{c}\text { Im-06-02-50- } \\
\text { 004-15- } \\
000025\end{array}$ & $\begin{array}{l}\text { Tratamiento de la } \\
\text { Semilla de Papa }\end{array}$ & $\begin{array}{c}\text { Conocimientos y } \\
\text { Usos Relacionados } \\
\text { con la Naturaleza } \\
\text { y el Universo } \\
\end{array}$ & $\begin{array}{l}\text { Técnicas y } \\
\text { Saberes } \\
\text { Productivos } \\
\text { Tradicionales }\end{array}$ & N/A \\
\hline $\begin{array}{l}\text { Im-06-02-50- } \\
\text { 004-15- } \\
000026\end{array}$ & $\begin{array}{l}\text { Almacenamiento de } \\
\text { Granos en Troje }\end{array}$ & $\begin{array}{c}\text { Conocimientos y } \\
\text { Usos Relacionados } \\
\text { con la Naturaleza } \\
\text { y el Universo }\end{array}$ & $\begin{array}{c}\text { Técnicas y } \\
\text { Saberes } \\
\text { Productivos } \\
\text { Tradicionales }\end{array}$ & N/A \\
\hline $\begin{array}{l}\text { Im-06-02-50- } \\
\text { 004-15- } \\
000027\end{array}$ & Rotación de Cultivos & $\begin{array}{l}\text { Conocimientos y } \\
\text { Usos Relacionados } \\
\text { con la Naturaleza } \\
\text { y el Universo } \\
\end{array}$ & $\begin{array}{l}\text { Técnicas y } \\
\text { Saberes } \\
\text { Productivos } \\
\text { Tradicionales } \\
\end{array}$ & $\begin{array}{c}\text { Conocimientos y Usos } \\
\text { Tradicionales de } \\
\text { Plantas, Animales y } \\
\text { Minerales } \\
\end{array}$ \\
\hline $\begin{array}{c}\text { Im-06-02-50- } \\
\text { 004-15- } \\
000028\end{array}$ & $\begin{array}{c}\text { Abonadura del Suelo } \\
\text { Con Majada De } \\
\text { Animales }\end{array}$ & $\begin{array}{l}\text { Conocimientos y } \\
\text { Usos Relacionados } \\
\text { con la Naturaleza } \\
\text { y el Universo } \\
\end{array}$ & $\begin{array}{c}\text { Técnicas y } \\
\text { Saberes } \\
\text { Productivos } \\
\text { Tradicionales } \\
\end{array}$ & N/A \\
\hline $\begin{array}{c}\text { Im-06-02-50- } \\
\text { 004-15- } \\
000029\end{array}$ & $\begin{array}{c}\text { Terrazas de } \\
\text { Formación Lenta }\end{array}$ & $\begin{array}{c}\text { Conocimientos y } \\
\text { Usos Relacionados } \\
\text { con la Naturaleza } \\
\text { y el Universo } \\
\end{array}$ & $\begin{array}{l}\text { Sabiduría } \\
\text { Ecológica } \\
\text { Tradicional }\end{array}$ & $\begin{array}{c}\text { Conocimientos y Usos } \\
\text { Tradicionales de } \\
\text { Plantas, Animales y } \\
\text { Minerales } \\
\end{array}$ \\
\hline $\begin{array}{c}\text { Im-06-02-50- } \\
\text { 004-15- } \\
000030\end{array}$ & $\begin{array}{c}\text { Riego Por Surcos O } \\
\text { Canalillos }\end{array}$ & $\begin{array}{c}\text { Conocimientos y } \\
\text { Usos Relacionados } \\
\text { con la Naturaleza } \\
\text { y el Universo }\end{array}$ & $\begin{array}{c}\text { Técnicas y } \\
\text { Saberes } \\
\text { Productivos } \\
\text { Tradicionales }\end{array}$ & N/A \\
\hline $\begin{array}{l}\text { Im-06-02-50- } \\
\text { 004-15- } \\
000031\end{array}$ & Yunta Para el Arado & $\begin{array}{l}\text { Conocimientos y } \\
\text { Usos Relacionados } \\
\text { con la Naturaleza } \\
\text { y el Universo } \\
\end{array}$ & $\begin{array}{c}\text { Técnicas y } \\
\text { Saberes } \\
\text { Productivos } \\
\text { Tradicionales } \\
\end{array}$ & N/A \\
\hline $\begin{array}{c}\text { Im-06-02-50- } \\
\text { 004-15- } \\
000032\end{array}$ & $\begin{array}{c}\text { Remedios } \\
\text { Fitosanitarios para } \\
\text { Cultivos }\end{array}$ & $\begin{array}{c}\text { Conocimientos y } \\
\text { Usos Relacionados } \\
\text { con la Naturaleza } \\
\text { y el Universo }\end{array}$ & $\begin{array}{l}\text { Sabiduría } \\
\text { Ecológica } \\
\text { Tradicional }\end{array}$ & $\begin{array}{c}\text { Conocimientos y Usos } \\
\text { Tradicionales de } \\
\text { Plantas, Animales y } \\
\text { Minerales } \\
\end{array}$ \\
\hline $\begin{array}{c}\text { Im-06-02-50- } \\
\text { 004-15- } \\
000033\end{array}$ & $\begin{array}{c}\text { Técnicas Ancestrales } \\
\text { de Siembra }\end{array}$ & $\begin{array}{l}\text { Conocimientos y } \\
\text { Usos Relacionados } \\
\text { con la Naturaleza } \\
\text { y el Universo } \\
\end{array}$ & $\begin{array}{l}\text { Sabiduría } \\
\text { Ecológica } \\
\text { Tradicional }\end{array}$ & $\begin{array}{c}\text { Conocimientos y Usos } \\
\text { Tradicionales de } \\
\text { Plantas, Animales y } \\
\text { Minerales } \\
\end{array}$ \\
\hline $\begin{array}{c}\text { Im-06-02-50- } \\
\text { 004-15- } \\
000034\end{array}$ & Predicción del Clima & $\begin{array}{c}\text { Conocimientos y } \\
\text { Usos Relacionados } \\
\text { con la Naturaleza } \\
\text { y el Universo }\end{array}$ & $\begin{array}{l}\text { Sabiduría } \\
\text { Ecológica } \\
\text { Tradicional }\end{array}$ & $\begin{array}{c}\text { Conocimientos y Usos } \\
\text { Tradicionales de } \\
\text { Plantas, Animales y } \\
\text { Minerales }\end{array}$ \\
\hline $\begin{array}{c}\text { Im-06-02-50- } \\
\text { 004-15- } \\
000035\end{array}$ & Parva de Kallcha & $\begin{array}{c}\text { Conocimientos y } \\
\text { Usos Relacionados } \\
\text { Con La Naturaleza } \\
\text { Y El Universo }\end{array}$ & $\begin{array}{l}\text { Sabiduría } \\
\text { Ecológica } \\
\text { Tradicional }\end{array}$ & $\begin{array}{c}\text { Conocimientos y Usos } \\
\text { Tradicionales de } \\
\text { Plantas, Animales y } \\
\text { Minerales } \\
\end{array}$ \\
\hline $\begin{array}{c}\text { Im-06-02-50- } \\
\text { 004-15- } \\
000036\end{array}$ & $\begin{array}{c}\text { Principales Cultivos } \\
\text { Tradicionales }\end{array}$ & $\begin{array}{c}\text { Conocimientos y } \\
\text { Usos Relacionados } \\
\text { Con la Naturaleza } \\
\text { y el Universo } \\
\end{array}$ & $\begin{array}{l}\text { Técnicas y } \\
\text { Saberes } \\
\text { Productivos } \\
\text { Tradicionales }\end{array}$ & N/A \\
\hline $\begin{array}{c}\text { Im-06-02-50- } \\
\text { 004-15- } \\
000037\end{array}$ & Papas con Cuy & $\begin{array}{c}\text { Conocimientos y } \\
\text { Usos Relacionados } \\
\text { con la Naturaleza } \\
\text { y el Universo }\end{array}$ & Gastronomía & Gastronomía Festiva \\
\hline Im-06-02-50- & Plato Típico El & Conocimientos y & Gastronomía & Gastronomía Festiva \\
\hline
\end{tabular}




\begin{tabular}{|c|c|c|c|c|}
\hline $\begin{array}{l}004-15- \\
000038\end{array}$ & Mediano & $\begin{array}{c}\text { Usos Relacionados } \\
\text { con la Naturaleza } \\
\text { y el Universo }\end{array}$ & & \\
\hline $\begin{array}{c}\text { Im-06-02-50- } \\
\text { 004-15- } \\
000039\end{array}$ & Chicha de Jora & $\begin{array}{l}\text { Conocimientos y } \\
\text { Usos Relacionados } \\
\text { con la Naturaleza } \\
\text { y el Universo } \\
\end{array}$ & Gastronomía & Gastronomía Festiva \\
\hline $\begin{array}{c}\text { Im-06-02-50- } \\
\text { 004-15- } \\
000040\end{array}$ & Chaguarmishqui & $\begin{array}{c}\text { Conocimientos y } \\
\text { Usos Relacionados } \\
\text { con la Naturaleza } \\
\text { y el Universo } \\
\end{array}$ & Gastronomía & Gastronomía Festiva \\
\hline $\begin{array}{c}\text { Im-06-02-50- } \\
\text { 004-15- } \\
000041\end{array}$ & Medicina Tradicional & $\begin{array}{l}\text { Conocimientos y } \\
\text { Usos Relacionados } \\
\text { con la Naturaleza } \\
\text { y el Universo }\end{array}$ & $\begin{array}{c}\text { Medicina } \\
\text { Tradicional }\end{array}$ & N/A \\
\hline $\begin{array}{c}\text { Im-06-02-50- } \\
\text { 004-15- } \\
000042\end{array}$ & Cerro Chiripungo & $\begin{array}{c}\text { Conocimientos y } \\
\text { Usos Relacionados } \\
\text { con la Naturaleza } \\
\text { y el Universo }\end{array}$ & $\begin{array}{c}\text { Espacios } \\
\text { Simbólicos }\end{array}$ & Sitios Sagrados \\
\hline $\begin{array}{c}\text { Im-06-02-50- } \\
\text { 004-15- } \\
000043\end{array}$ & $\begin{array}{l}\text { Cerro Cóndor } \\
\text { Puñuna }\end{array}$ & $\begin{array}{l}\text { Conocimientos y } \\
\text { Usos Relacionados } \\
\text { con la Naturaleza } \\
\text { y el Universo }\end{array}$ & $\begin{array}{c}\text { Espacios } \\
\text { Simbólicos }\end{array}$ & Sitios Sagrados \\
\hline $\begin{array}{c}\text { Im-06-02-50- } \\
\text { 004-15- } \\
000044\end{array}$ & Cuy Rumi & $\begin{array}{c}\text { Conocimientos y } \\
\text { Usos Relacionados } \\
\text { con la Naturaleza } \\
\text { y el Universo }\end{array}$ & $\begin{array}{l}\text { Espacios } \\
\text { Simbólicos }\end{array}$ & Sitios Sagrados \\
\hline $\begin{array}{c}\text { Im-06-02-50- } \\
\text { 004-15- } \\
000045\end{array}$ & Camino del Inca & $\begin{array}{l}\text { Conocimientos y } \\
\text { Usos Relacionados } \\
\text { con la Naturaleza } \\
\text { y el Universo }\end{array}$ & $\begin{array}{c}\text { Espacios } \\
\text { Simbólicos }\end{array}$ & Sitios Sagrados \\
\hline $\begin{array}{c}\text { Im-06-02-50- } \\
\text { 004-15- } \\
000046\end{array}$ & Chaquiñanes & $\begin{array}{c}\text { Conocimientos y } \\
\text { Usos Relacionados } \\
\text { con la Naturaleza } \\
\text { y el Universo }\end{array}$ & $\begin{array}{c}\text { Espacios } \\
\text { Simbólicos }\end{array}$ & Sitios Sagrados \\
\hline $\begin{array}{c}\text { Im-06-02-50- } \\
\text { 004-15- } \\
000047\end{array}$ & $\begin{array}{l}\text { Toponimia del } \\
\text { Nombre Nizag }\end{array}$ & $\begin{array}{l}\text { Conocimientos y } \\
\text { Usos Relacionados } \\
\text { con la Naturaleza } \\
\text { y el Universo }\end{array}$ & Toponimia & N/A \\
\hline $\begin{array}{c}\text { Im-06-02-50- } \\
\text { 004-15- } \\
000048\end{array}$ & $\begin{array}{l}\text { Antroponimia del } \\
\text { Pueblo Nizag }\end{array}$ & $\begin{array}{l}\text { Conocimientos y } \\
\text { Usos Relacionados } \\
\text { con la Naturaleza } \\
\text { y el Universo } \\
\end{array}$ & Toponimia & N/A \\
\hline $\begin{array}{c}\text { Im-06-02-50- } \\
\text { 005-15- } \\
000049 \\
\end{array}$ & $\begin{array}{c}\text { Tejido con Lana de } \\
\text { Borrego }\end{array}$ & $\begin{array}{c}\text { Técnicas } \\
\text { Artesanales } \\
\text { Tradicionales } \\
\end{array}$ & $\begin{array}{c}\text { Técnicas } \\
\text { Artesanales } \\
\text { Tradicionales }\end{array}$ & $\begin{array}{l}\text { Tejido con Fibras } \\
\text { Naturales }\end{array}$ \\
\hline $\begin{array}{c}\text { Im-06-02-50- } \\
005-15- \\
000050 \\
\end{array}$ & Tejido con Cabuya & $\begin{array}{c}\text { Técnicas } \\
\text { Artesanales } \\
\text { Tradicionales } \\
\end{array}$ & $\begin{array}{c}\text { Técnicas } \\
\text { Artesanales } \\
\text { Tradicionales }\end{array}$ & $\begin{array}{l}\text { Tejido con Fibras } \\
\text { Naturales }\end{array}$ \\
\hline $\begin{array}{c}\text { Im-06-02-50- } \\
005-15- \\
000051 \\
\end{array}$ & $\begin{array}{c}\text { Técnicas } \\
\text { Constructivas }\end{array}$ & $\begin{array}{c}\text { Técnicas } \\
\text { Artesanales } \\
\text { Tradicionales } \\
\end{array}$ & $\begin{array}{c}\text { Técnicas } \\
\text { Constructivas } \\
\text { Tradicionales } \\
\end{array}$ & $\begin{array}{c}\text { Técnica en Barro } \\
\text { Crudo }\end{array}$ \\
\hline $\begin{array}{c}\text { Im-06-02-50- } \\
\text { 005-15- } \\
000052 \\
\end{array}$ & Trapiche con Yunta & $\begin{array}{c}\text { Técnicas } \\
\text { Artesanales } \\
\text { Tradicionales }\end{array}$ & $\begin{array}{c}\text { Técnicas } \\
\text { Constructivas } \\
\text { Tradicionales } \\
\end{array}$ & N/A \\
\hline
\end{tabular}


Nota: En (Urgilez, 2015, pág. 230)

N/A: Significa que No Aplica un sub-ámbito según la metodología utilizada.

Se identificaron 52 manifestaciones que reflejan el patrimonio cultural inmaterial enraizado en la memoria viva de sus habitantes, manifestándose prioritariamente en el ámbito de "Conocimientos y Usos Relacionados con la Naturaleza y el Universo" con un total de 24 manifestaciones que representan el 46\%; respecto al ámbito "Usos Sociales y Actos Festivos" se registraron 12 manifestaciones que representan el 23\%; relacionado al ámbito "Tradiciones y Expresiones Orales” se identificaron 7 manifestaciones que representan el 13\%; respecto al ámbito "Artes del Espectáculo" se identificaron 5 manifestaciones que representan el 10\%; y el ámbito "Técnicas Artesanales Tradicionales" un total de 4 manifestaciones que representan el $8 \%$.

\section{Análisis situacional de las manifestaciones culturales}

Cuadro 2: Matriz de evaluación del patrimonio cultural inmaterial y de la memoria viva

\begin{tabular}{|c|c|c|c|c|c|c|c|c|}
\hline $\mathrm{N}^{\circ}$ & MANIFESTACIÓN & 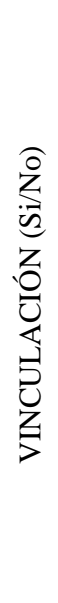 & 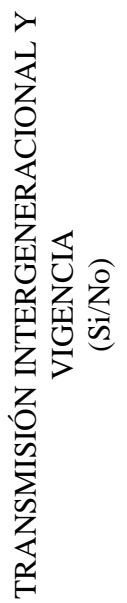 & 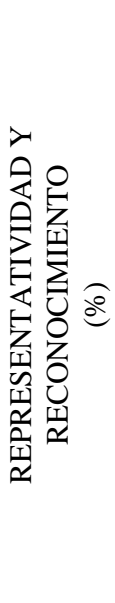 & 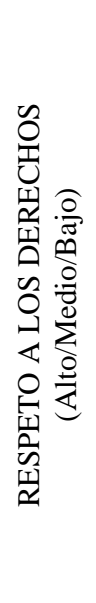 & 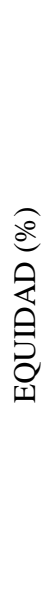 & 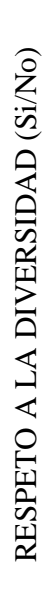 & 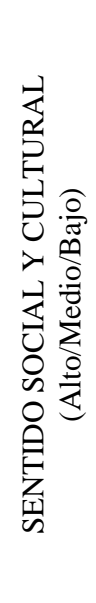 \\
\hline 1 & Leyenda Cóndor Puñuna & No & No & 50 & Medio & 25 & $\mathrm{Si}$ & Medio \\
\hline 2 & Leyenda Cruzpamba & No & No & 50 & Medio & 25 & $\mathrm{Si}$ & Medio \\
\hline 3 & Leyenda Abra la Puerta Señora & No & No & 50 & Medio & 25 & $\mathrm{Si}$ & Medio \\
\hline 4 & Leyenda Novio Cóndor & No & No & 100 & Medio & 50 & $\mathrm{Si}$ & Alto \\
\hline 5 & Cuento Wantugaya & No & No & 25 & Bajo & 25 & $\mathrm{Si}$ & Bajo \\
\hline 6 & Coplas de Carnaval & $\mathrm{Si}$ & $\mathrm{Si}$ & 75 & Alta & 75 & $\mathrm{Si}$ & Alto \\
\hline 7 & $\begin{array}{l}\text { Supersticiones, dichos y } \\
\text { creencias }\end{array}$ & No & No & 50 & Medio & 25 & $\mathrm{Si}$ & Medio \\
\hline 8 & Danza Los Yumbos & $\mathrm{Si}$ & No & 75 & Alta & 50 & $\mathrm{Si}$ & Alto \\
\hline 9 & Danza El Capitán & Si & No & 50 & Alta & 50 & $\mathrm{Si}$ & Medio \\
\hline 10 & Danza El Tejido De Cintas & $\mathrm{Si}$ & $\mathrm{Si}$ & 75 & Alta & 75 & $\mathrm{Si}$ & Alto \\
\hline 11 & Juegos tradicionales & No & $\mathrm{Si}$ & 50 & Medio & 50 & $\mathrm{Si}$ & Medio \\
\hline 12 & Haway & $\mathrm{Si}$ & No & 50 & Alta & 25 & $\mathrm{Si}$ & Medio \\
\hline 13 & Fiesta Hotava & No & $\mathrm{Si}$ & 75 & Medio & 75 & $\mathrm{Si}$ & Medio \\
\hline 14 & Fiesta Tres Reyes & $\mathrm{Si}$ & No & 25 & Medio & 25 & $\mathrm{Si}$ & Medio \\
\hline
\end{tabular}




\begin{tabular}{|c|c|c|c|c|c|c|c|c|}
\hline 15 & Fiesta Tayta Carnaval & $\mathrm{Si}$ & No & 50 & Medio & 50 & Si & Medio \\
\hline 16 & Fiesta Corpus Christi & $\mathrm{Si}$ & No & 50 & Alta & 50 & Si & Alto \\
\hline 17 & Día de los Difuntos & No & $\mathrm{Si}$ & 50 & Medio & 50 & Si & Medio \\
\hline 18 & Concurso de años viejos & No & $\mathrm{Si}$ & 25 & Medio & 25 & Si & Bajo \\
\hline 19 & La minga y presta mano & $\mathrm{Si}$ & Si & 100 & Alta & 100 & Si & Alto \\
\hline 20 & Pampamesa & No & Si & 25 & Medio & 50 & Si & Medio \\
\hline 21 & Fiesta de la cosecha & $\mathrm{Si}$ & $\mathrm{Si}$ & 50 & Medio & 50 & Si & Medio \\
\hline 22 & $\begin{array}{l}\text { Ritos asociados al nacimiento } \\
\text { de un niño }\end{array}$ & $\mathrm{Si}$ & $\mathrm{Si}$ & 75 & Medio & 50 & $\mathrm{Si}$ & Medio \\
\hline 23 & Enamoramiento y matrimonio & No & No & 50 & Medio & 50 & $\mathrm{Si}$ & Medio \\
\hline 24 & El Funeral & No & No & 25 & Medio & 50 & Si & Medio \\
\hline 25 & $\begin{array}{c}\text { Tratamiento de la semilla de } \\
\text { papa }\end{array}$ & No & $\mathrm{Si}$ & 50 & Bajo & 25 & $\mathrm{Si}$ & Bajo \\
\hline 26 & $\begin{array}{c}\text { Almacenamiento de granos en } \\
\text { troje }\end{array}$ & No & No & 25 & Bajo & 25 & $\mathrm{Si}$ & Bajo \\
\hline 27 & Rotación de cultivos & No & $\mathrm{Si}$ & 75 & Medio & 75 & Si & Alto \\
\hline 28 & $\begin{array}{l}\text { Abonadura del suelo con } \\
\text { majada de animales }\end{array}$ & No & $\mathrm{Si}$ & 75 & Medio & 75 & $\mathrm{Si}$ & Medio \\
\hline 29 & Terrazas de formación lenta & No & No & 25 & Bajo & 25 & Si & Bajo \\
\hline 30 & Riego por surcos o canalillos & No & $\mathrm{Si}$ & 100 & Alta & 50 & Si & Alto \\
\hline 31 & Yunta para el arado & $\mathrm{Si}$ & $\mathrm{Si}$ & 100 & Alta & 100 & $\mathrm{Si}$ & Alto \\
\hline 32 & $\begin{array}{l}\text { Remedios fitosanitarios para } \\
\text { cultivos }\end{array}$ & $\mathrm{Si}$ & $\mathrm{Si}$ & 25 & Medio & 50 & $\mathrm{Si}$ & Medio \\
\hline 33 & Técnicas ancestrales de siembra & $\mathrm{Si}$ & No & 25 & Bajo & 50 & $\mathrm{Si}$ & Medio \\
\hline 34 & Predicción del clima & No & $\mathrm{Si}$ & 50 & Bajo & 50 & $\mathrm{Si}$ & Medio \\
\hline 35 & Parva de Kallcha & No & $\mathrm{Si}$ & 100 & Alta & 100 & $\mathrm{Si}$ & Alto \\
\hline 36 & $\begin{array}{l}\text { Principales cultivos } \\
\text { tradicionales } \\
\end{array}$ & No & Si & 75 & Medio & 50 & $\mathrm{Si}$ & Medio \\
\hline 37 & Papas con cuy & No & $\mathrm{Si}$ & 25 & Medio & 50 & $\mathrm{Si}$ & Medio \\
\hline 38 & Plato típico el mediano & $\mathrm{Si}$ & Si & 25 & Medio & 50 & $\mathrm{Si}$ & Medio \\
\hline 39 & Chicha de jora & $\mathrm{Si}$ & Si & 100 & Alta & 100 & $\mathrm{Si}$ & Alto \\
\hline 40 & Chaguarmishqui & $\mathrm{Si}$ & Si & 25 & Medio & 50 & $\mathrm{Si}$ & Medio \\
\hline 41 & Medicina Tradicional & $\mathrm{Si}$ & Si & 100 & Alta & 100 & $\mathrm{Si}$ & Alto \\
\hline 42 & Cerro Chiripungo & $\mathrm{Si}$ & $\mathrm{Si}$ & 75 & Alta & 75 & $\mathrm{Si}$ & Alta \\
\hline 43 & Cerro Cóndor Puñuna & $\mathrm{Si}$ & $\mathrm{Si}$ & 100 & Alta & 100 & $\mathrm{Si}$ & Alta \\
\hline 44 & Cuy Rumi & No & Si & 50 & Medio & 50 & $\mathrm{Si}$ & Media \\
\hline 45 & Qhapac Ñan & $\mathrm{Si}$ & $\mathrm{Si}$ & 75 & Alta & 75 & $\mathrm{Si}$ & Alta \\
\hline 46 & Chaquiñanes & No & Si & 75 & Alta & 75 & $\mathrm{Si}$ & Alta \\
\hline 47 & Toponimia del nombre Nizag & No & No & 50 & Medio & 50 & $\mathrm{Si}$ & Medio \\
\hline 48 & Antroponimia del pueblo Nizag & No & $\mathrm{Si}$ & 25 & Medio & 50 & $\mathrm{Si}$ & Medio \\
\hline 49 & Tejido con lana de borrego & $\mathrm{Si}$ & Si & 50 & Medio & 50 & $\mathrm{Si}$ & Medio \\
\hline 50 & Tejido con cabuya & $\mathrm{Si}$ & Si & 75 & Alta & 75 & Si & Alta \\
\hline 51 & Técnicas constructivas & $\mathrm{Si}$ & No & 50 & Medio & 50 & $\mathrm{Si}$ & Medio \\
\hline 52 & Trapiche con yunta & $\mathrm{Si}$ & $\mathrm{Si}$ & 75 & Alta & 75 & $\mathrm{Si}$ & Alta \\
\hline
\end{tabular}

Nota: En (Urgilez Pinos, 2016, pág. 50)

\section{a. Vinculación a los ámbitos del Patrimonio Cultural Inmaterial}

La comunidad reconoce como Patrimonio Cultural Inmaterial Local de un total de 52 manifestaciones a 25 de ellas. Las 25 manifestaciones se enmarcan en la definición del Patrimonio Inmaterial establecida en la Convención para la Salvaguardia del Patrimonio Cultural Inmaterial, de la que el Ecuador es país signatario. 
b. Transmisión intergeneracional y vigencia

De las 52 manifestaciones, 33 de estas, ligadas a los conocimientos, saberes, técnicas y prácticas se heredan de generación en generación. Esto indica que el 64\% de transmisión intergeneracional. Además de este proceso continuo de transmisión de los saberes, los significados son recreados en función de los contextos sociales, económicos, políticos o culturales manteniéndose la vigencia de cada una de ellas.

c. Representatividad y reconocimiento comunitario y/o colectivo

Las manifestaciones que son representativas y dan creencia, teniendo en cuenta la relevancia histórica, significación social, valoración y reconocimiento comunitario como parte de su identidad y sentido de pertenencia son: la Leyenda Novio Cóndor, la Minga y Presta Mano, Riego por Surcos o Canalillos, Yunta para el Arado, Parva de Kallcha, Chicha de Jora, Medicina Tradicional y el Cerro Cóndor Puñuna; cada uno con un puntaje de 100\%. Seguido del 75\% por las Coplas de Carnaval, Danza Los Yumbos, Danza el Tejido de Cintas, Fiesta de Hotava, Ritos asociados al nacimiento de un niño, Rotación de Cultivos, Abonadura del suelo con majada de animales, principales cultivos tradicionales, Cerro Chiripungo, Camino del Inca, Chaquiñanes, Tejido con Cabuya y Trapiche con Yunta.

\section{d. Respeto a los derechos}

Se identifican 18 manifestaciones de un total de 52, que se enmarcan en un alto nivel de respeto a los derechos humanos, derechos colectivos y de la naturaleza.

\section{e. $\quad$ Equidad}

Las expresiones culturales que indican una equidad al 100\% tomando en cuenta que estas manifestaciones promueven la solidaridad, la cohesión social, la reciprocidad y contienen valores que fomentan el bienestar social y colectivo son: la Minga y Presta Mano, Yunta para el arado, Parva de Kallcha, Chicha de Jora, Medicina Tradicional y el cerro Cóndor Puñuna.

\section{f. Respeto a la diversidad}

Todas las manifestaciones inventariadas (52), se enmarcan en el respeto a la diversidad y no promueven conflictos de discriminación étnica, racial o social.

g. Sentido social y comunitario

Las 29 expresiones constituyen un nivel medio con relación al sentido social y cultural, 18 de ellas un nivel alto y tan solo 5 un nivel bajo. 


\section{Conclusión}

La puesta en valor del patrimonio cultural inmaterial de la comunidad de Nizag aporta a su sentido de pertenencia y sostenibilidad, con la identificación de 52 manifestaciones culturales que reflejan la trasmisión intergeneracional que se manifiesta en el enraizado conocimiento ancestral de sus habitantes. La vigencia de las manifestaciones culturales muestran la prioridad del ámbito de «conocimientos y usos relacionados con la naturaleza y el universo», específicamente en el subámbito de técnicas y saberes productivos tradicionales. En consecuencia desde la reflexión social la visibilización del patrimonio fortalece la identidad y el componente organizativo, que permite recrear sus tradiciones con una profunda conexión al territorio, lo que asegura su permanencia en el tiempo y su función como una herramienta de desarrollo local y para el Buen Vivir de los pueblos.

\section{References:}

Aguirre Merino, C. P. (2015). Puñay, El Secreto de una Pirámide (Vol. I). Quito, Ecuador: Caracoles.

Centro de Información de las Naciones Unidas. (22 de Agosto de 2002). La importancia del patrimonio cultural. Recuperado el 18 de Febrero de 2016, de Naciones

Unidas:

http://www.cinu.org.mx/eventos/cultura2002/importa.htm

Coordinación General de Estadística e Investigación del Ministerio de Turismo del Ecuador. (20 de Abril de 2015). Boletín trimetral. Información relevante del turismo en el Ecuador. I Trimestre del año 2015. Quito, Pichincha, Ecuador.

Goberno Autónomo Descentralizado Cantonal de Alausí. (2014). Plan de Ordenamiento Territorial del Cantón Alausí. GAD Cantonal Alausí, Alausí.

Guerrero Arias, P. (2002). Guía etnográfica. Quito, Pichincha, Ecuador: Ediciones Abya-Yala.

Instituto Nacional de Patrimonio Cultural del Ecuador. (24 de Enero de 2012). Instructivo para fichas de registro e inventario patrimonio cultural inmaterial. (Ediecuatorial). Quito, Pichincha, Ecuador.

Ministerio de Turismo del Ecuador. (Diciembre de 2007). Plan estratégico de desarrollo del turismo sostenible en Ecuador hacia el año 2020 "PLANDETUR 2020". Quito, Pichincha, Ecuador.

Ministerio del Ambiente, EcoCiencia, Unión Mundial para la Naturaleza. (2001). La biodiversidad del Ecuador. informe 2000. Quito, Pichincha, Ecuador.

Organización de las Naciones Unidas para la Educación, la Ciencia y la Cultura. (22 de 06 de 2014). United Nations. Recuperado el 11 de 3 de 2016, de UNESCO World Heritage Centre: http://whc.unesco.org/archive/2014/whc14-38com-16en.pdf 
Organización de las Naciones Unidas para la Educación, la Ciencia y la Tecnología. (18 de Febrero de 2016). ¿Qué es el patrimonio cultural inmaterial? Recuperado el 18 de Febrero de 2016, de www.unesco.org: http://www.unesco.org/culture/ich/es/que-es-el-patrimonio-inmaterial-00003 Organización Mundial de Turismo. (12 de Febrero de 2016). Entender el turismo: glosario básico. Recuperado el 12 de Febrero de 2016, de http://media.unwto.org: http://media.unwto.org/es/content/entender-elturismo-glosario-basico

Organización Mundial del Turismo. (13 de Julio de 2015). Panorama OMT del turismo internacional. Recuperado el 12 de Febrero de 2016, de http://www.e-unwto.org:

unwto.org/doi/pdf/10.18111/9789284416875

http://www.e-

Organización Mundial del Turismo. (13 de Febrero de 2016). Sustainable development of tourism. Recuperado el 13 de Febrero de 2016, de http://sdt.unwto.org/es: http://sdt.unwto.org/es

Programa de las Naciones Unidas para el Medio Ambiente. (21 de Marzo de 2002). Convenio sobre la diversidad biológica. Recuperado el 9 de Marzo de 2016, de https://www.cbd.int/: https://www.cbd.int/doc/meetings/cop/cop06/information/cop-06-inf-33-es.pdf

Secretaría Nacional de Planificación y Desarrollo. (19 de Septiembre de 2014). Plan Nacional para el Buen Vivir 2013-2017. Quito, Pichincha, Ecuador.

Urgilez Pinos, L. L. (2 de Marzo de 2016). Plan de salvaguardia del patrimonio cultural inmaterial de la comunidad Nizag, cantón Alausí, provincia de Chimborazo. Riobamba, Chimborazo, Ecuador.

Urgilez, L. L. (20 de Febrero de 2015). Inventario del patrimonio cultural inmaterial y de la memoria viva de la comunidad Nizag, perteneciente a la parroquia Matriz, cantón Alausí, provincia de Chimborazo. Riobamba, Chimborazo, Ecuador. 


\section{Anexos}

\section{Anexo A}

Ficha de registro para el inventario de patrimonio cultural inmaterial de la comunidad de Nizag.

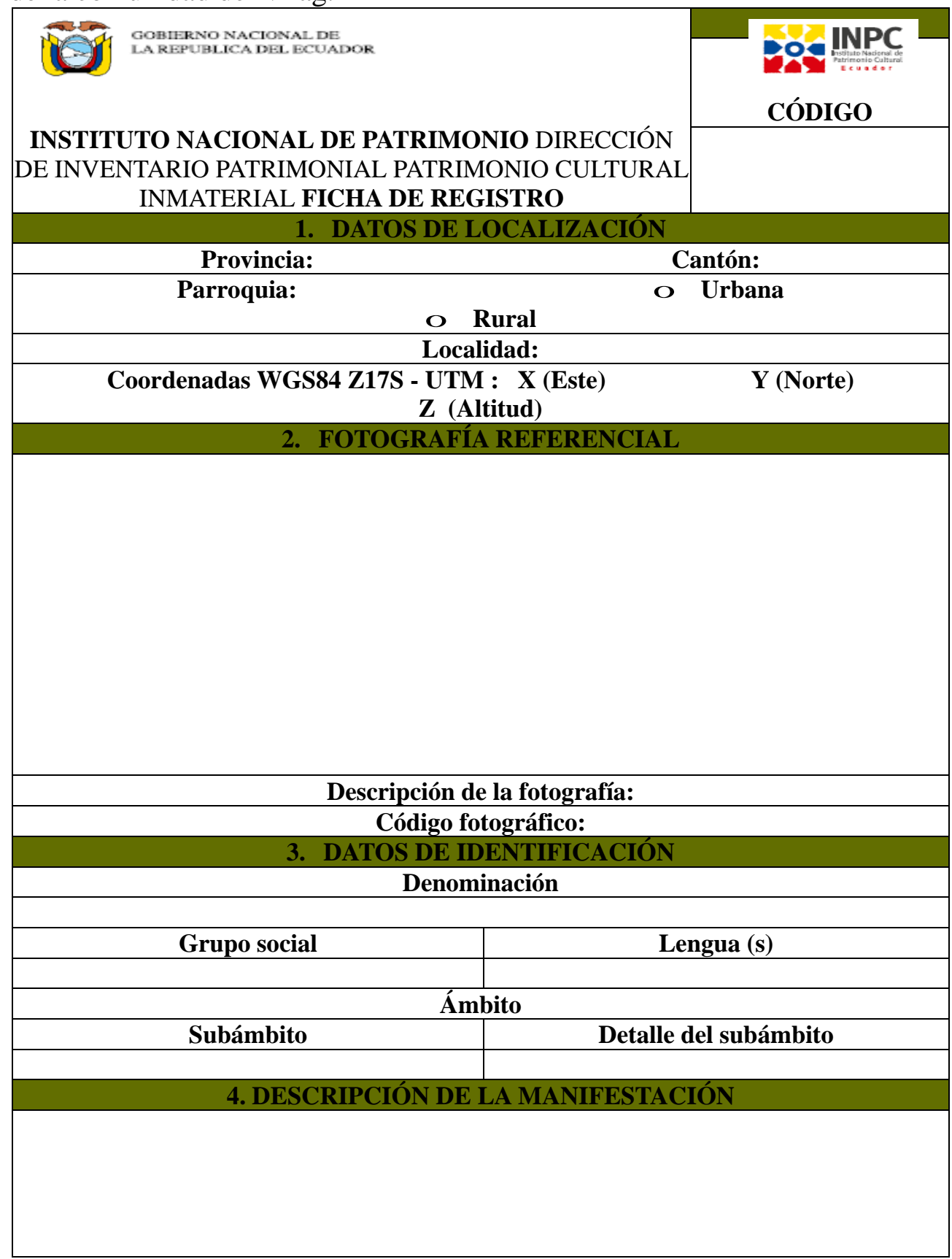




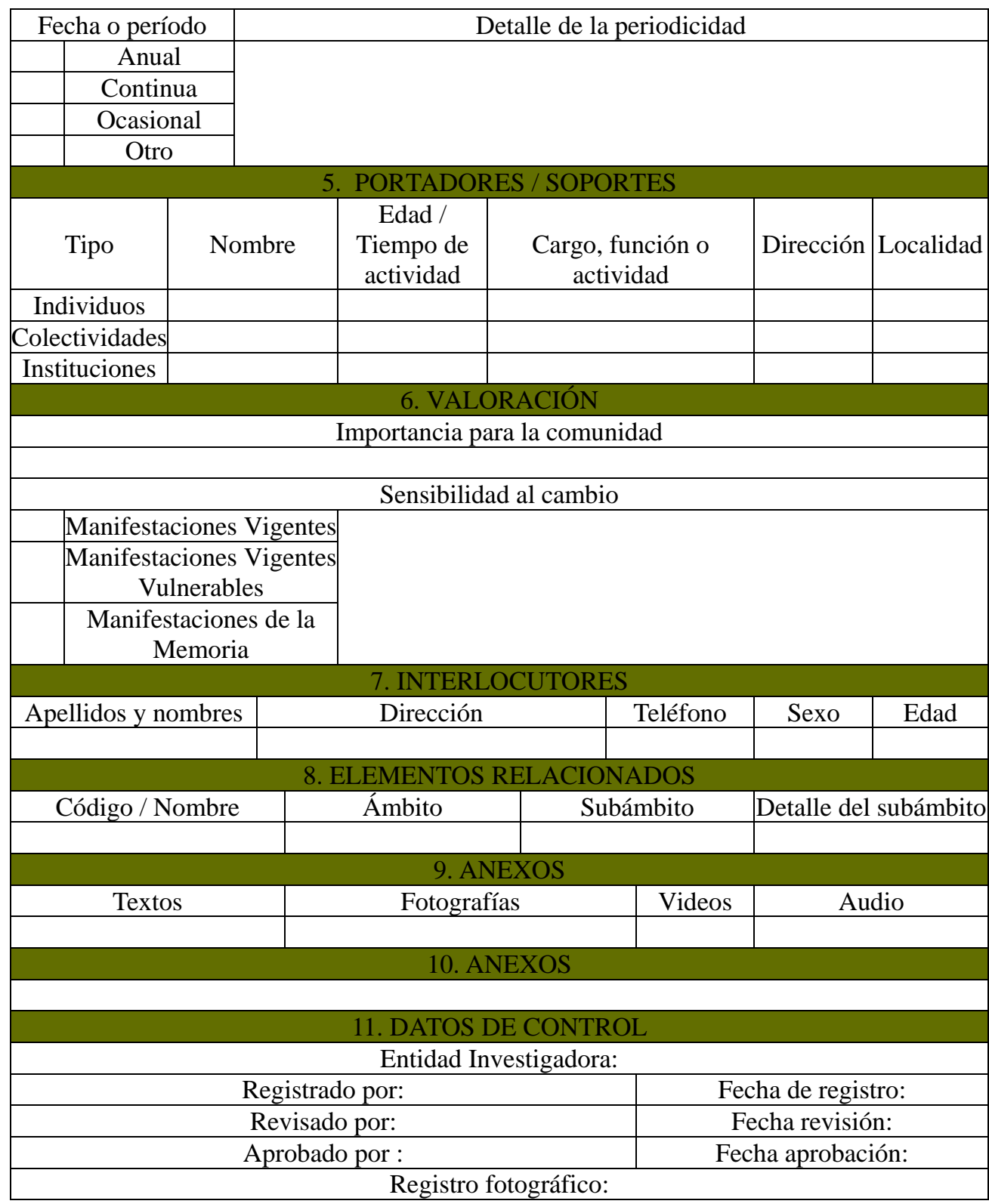

Nota: En (Instituto Nacional de Patrimonio Cultural del Ecuador, 2012, pág. 165) 